\title{
Factors Affecting Restaurant Consumers' Tipping Behavior
}

\author{
Cho, Sun $\mathrm{Bai}^{*+}$ \\ * Professor of Department of Hotel Management of Cheongju University
}

\begin{abstract}
This study examines the relationship between tip amount and its possible antecedents: bill size, the Big Five personality types, meal type, food quality, atmosphere, service quality, consumer gender, server gender, customer hospitality experience, race, and alcohol consumption. A survey of southeastern undergraduate students was conducted to collect information about the customer, server and customer tipping habits. While the analysis suggests that service is an important factor, it shows that other factors affect tip amount. Furthermore, these factors affect tip amounts in many different ways. Some examples of these factors include bill size, alcohol consumption, gender dynamics, meal type, food quality, and personality type. The conclusion suggests the intuition behind these factors by providing a dissection of their meaning and their importance to servers, customers, and managers alike.
\end{abstract}

Purpose: This study tests restaurant customer tipping habits and some personality traits that have received limited previous attention as predictors of tipping.

Methods: This study is that the tip amount was self-reported, business students at a university in a large southeastern city of USA were asked to complete a tipping journal.

Results: This study was able to replicate the service-tipping relationship. Moreover, this study reiterated that server friendliness is a very powerful tool to increasing tips.

Conclusion: This study strongly indicate that service has a positive relationship with tip amount, and also produce a positive relationship with emotional stability and a negative relationship to conscientiousness.

Key Words: Tipping, Restaurant, Gender Dynamics, Personality Type

- Received 27 November 2013, revised 17 December 2013, accepted 19 December 2013

† Corresponding Author(johnap@hanmail.net)

(c) 2013, The Korean Society for Quality Management

This is an Open Access article distributed under the terms of the Creative Commons Attribution Non-Commercial License (http://creativecommons.org/licenses/by-nc/3.0) which permits unrestricted non-Commercial use, distribution, and reproduction in any medium, provided the original work is properly cited. 


\section{Introduction}

Over time, the custom of tipping has evolved from an occasional form of gratitude for good service into a social norm. In many cultures around the world, customers voluntarily leave tips for the workers that have served them. In the United States and Canada alone, tips in the restaurant industry amount to almost 40 billion dollars every year (Azar, 2009). Furthermore, tips affect millions of server's pay level and can often account for a large majority of servers' paycheck (Wessels, 1997). Therefore, understanding what motivates customers to tip is important from a theoretical and managerial perspective.

Many researchers have attempted to explain the social phenomenon of tipping. These studies have approached tipping from different viewpoints and across many different industries including bellman service, taxi service, food delivery, and restaurants (Azar, 2007). Out of all the studies conducted on tipping, hundreds of studies have been centered on tipping in the restaurant industry. It clearly indicates that restaurant is a representative industry to study the consumers'tipping behavior.

Tipping is used as the incentive that ensures quality service (Bodvarsson et al., 2003; Brewster, 2012a; Brewster, 2012b). However, this does not always hold true and service is not the only factor that affects tipping. If service quality and tip amount do not have a strong relationship, then perhaps other predictors affect tipping. Understanding what these variables are and what impact they have could help managers motivate servers to perform to the best of their ability, help servers to increase their paychecks, aid executives' efforts to expand into new geographic markets, and set optimal pricing (Schwartz, 1997) and tipping policies (Azar, 2003).

Regardless of significant improvements in understanding the motives of restaurant tipping behavior, a dearth of research was conducted to explore seemingly important predictors (alcoholic consumption and meal duration) of tipping. This paper contributes to the knowledge base of restaurant customer tipping habits by empirically testing such variables as dining experience indices, customer/server gender dynamics, alcohol consumption, and meal duration. In addition, this study tests some personality traits that have received limited previous attention as predictors of tipping. Potentially new interaction terms are also tested to see whether they have additional explanation power in explaining tipping behavior. This study investigates the moderating role of alcohol consumption between dining experience indices (e.g., food, atmosphere, and service) and tipping. Consumers with alcohol consumption are expected to moderate the relationship between the dining experience and tipping amount. In addition, this study tests the moderating role of bill size in the relationship between customer/server gender dynamic and tipping.

\section{Literature review}

From a theoretical standpoint, tipping can be viewed as an irrational behavior. The literature on tipping suggests that a tipping customer is not consistent with the economic model of rational and self-interested consumers (Azar, 2007). In other words, given that the service transaction has already occurred at the time 
of the tip, one would expect the economically rational patron to leave a zero tip amount. Furthermore, tips are not given until after service is delivered, so they are not necessary to ensure good service during that particular dinning experience. The fact that people tip despite these factors indicates that there are other reasons why people choose to tip. In turn, studies have approached tipping from many aspects. There could be many explanations for the desire to tip that include, ensuring future service from servers customers will encounter again, increase server's income, to experience positive feelings, to avoid negative feelings, to receive social approval, to avoid social disapproval, and to build honest character or to support the social norm of tipping (Lynn, 2006).

\subsection{Predictors of tipping}

By far, the majority of studies conducted about tipping involve an empirical analysis. As Azar (2007) summarizes, the majority of these empirical studies conducted on tipping involve an analysis that is conducted in the restaurant industry. Each of these methods seeks to explain tipping in a different way and from a different viewpoint. The methods of particular interest to this study are surveys of the general public, researchers working in collusion with the server, and customer restaurant exit interviews.

Many empirical studies attempt to create a relationship between tipping and other customer characteristics. Researchers have tried to attribute tipping behaviors to other variables such as server/customer gender dynamic, personality type, server/customer race, service quality, meal type, day of the week, etc (Azar, 2007). Lynn (2006)'s study is a cumulative review which summarizes that past studies have shown that service quality, bill size, and customer patronage frequency have positive relationships with tip size. Azar (2007) and Lynn (2006) categorize many of the same predictors as important when conveying the topic of empirical studies based on restaurant tipping. Potentially important predictors in the literature are described in detail as follows.

\subsection{Service quality}

Determining whether service quality has an impact on tip size is one of the most important aspects about tipping behavior (Azar 2007). The primary purpose of tipping is to provide an incentive for excellent service. However, As important as the service quality/tipping relationship is, many researchers have different opinions about the relationship. Lynn and McCall (2000) showed that parties that rate service quality highly leave larger tips than those parties who rate service less highly. However, the effect was relatively small as it can account for less than 2 percent to almost 5 percent of the tipping variability. Conlin et al. (2003) used a 5-point scale to measure service quality. They found that each extra point on their scale added 1.49 percentage points to the tipping amount. However, they also found that friendliness and speed of service had positive influence on tipping amount, appearance and attentiveness were not statistically significant, and knowledge had a statistically significant positive relationship with tipping. On the other hand, Lynn and Sturman (2010) showed that every extra point in service translated into an extra $2 \%$ of the 
bill tip. Kerr and Domazilcky (2009) found that there was a significantly negative relationship between time of food delivery and tip percentage.

\subsection{Patronage frequency}

Patronage frequency refers to the number of times a customer returns to the same establishment in a given time period. The question here is do tipping habits differ between first time customers and repeat customers. Lynn and McCall (2000) showed that frequent patrons tend to base their tip amount on a percentage of the bill size more often than do infrequent patrons. Furthermore, frequent patrons tend to tip a higher percentage compared to infrequent patrons. Conlin et al. (2003) also found a significant, positive correlation between tip size and patronage frequency.

\subsection{Bill size}

Because social norms in the United States call for tipping restaurant servers 15 to 20 percent of the bill, it is not surprising that bill size and tip amounts are positively correlated (Lynn 2006). Therefore, bill size is considered a non-controversial variable (Azar 2007). In fact, bill size could be the most important fact when determining the tip according to Bodvarsson and Gibson (1997). Lynn and McCall (2000) found that 69 percent of the within-restaurant variability in dollar tip amounts can be explained by bill size. This suggests that bill size is two times more powerful at predicting tip amount than all other factors combined (Lynn 2006).

Another question regarding bill size is its relationship with tipping percentage. Conlin et al. (2003) found that bill size negatively affects tip percentage. Green et al. (2003) had similar findings. In their article, Green et al. describe what they call 'the magnitude effect in tipping'. This means that as the size of the bill grows, the percentage based tip tends to level or fall off. There are many explanations for 'the magnitude effect for tipping'. For the most part, this effect can be explained because of the positive intercept between bill size and tip amount (Lynn and Sturman, 2003). Explanations for this positive intercept include, a tendency to leave minimum tip amount when the bill size is small (Lynn and Bond, 1992), a tendency to leave a constant amount to the percentage of the tip (Green et al, 2003), the fact that some people leave flat tips (Lynn and Sturman, 2003), or a tendency to round-up tip amounts to the nearest dollar (Azar, 2004). Of these explanations, only the flat tipper theory has been empirically proven true (Lynn and Sturman, 2003).

\subsection{Dining party size}

The evidence based on dining party size and its relationship to tipping is mixed (Azar 2007). Freeman et al. (1975), Lynn and Latane (1984), and May (1980) all found that large dining parties leave smaller percentage tips than do small dining parties. Lynn and Grassman (1990) found no correlation between group size and tipping. However, Conlin et al. (2003) found that tip percentage is positively correlated with group 
size.

\subsection{Server and customer gender dynamics}

While it has been shown that males leave higher tips than females (Crusco and Wetzel, 1984), other studies have suggested the opposite to be true (Lynn and Graves, 1996). Therefore, it seems that as far as gender is concerned, tipping size depends on the server/customer gender dynamic. It has been shown that males are more likely to tip female servers more and vice versa (Lynn, 2006). It has also been suggested that the gender relationship can be more clearly explained by sexual attraction (Conlin et al, 2003).

Lynn (2009) discussed the affect of server attractiveness on average tip percentage. This study, “indicated that waitresses in their 30' $\mathrm{s}$ and those with large breasts, blonde hair, and/or slender bodies received larger average tips than their counterparts without these characteristics (p.744).”

\subsection{Customer/Server Ethnicity}

Ethnicity is also a factor when predicting tip size. Kerr and Domazilcky (2009) found that African Americans tips were about six percentage points below the tips of White people. This could be due to the fact that Black patrons are more likely to tip based on a flat amount, and White patrons are more likely to tip on a percentage amount (Lynn 2006). Lynn (2006) also reports that Black people are more likely to leave a smaller tip amount (based on percentage) when compared to White people. Researchers have been able to rule out the impact of socio-economic and discrimination of service quality on the difference in tipping habits (Lynn, 2006). Furthermore, it has been shown that difference in tipping habits can be attributed to a lack of understanding of social norms (Lynn, 2011).

\subsection{Personality type}

While numerous studies have been conducted about tipping, the relationship between personality type and tip size has not been extensively tested. Lynn (2008) is a recent study that attempts to relate extraversion, neuroticism and psychoticism to the magnitude of tipping. This study demonstrated that levels of national extraversion and psychoticism are related to customary tip sizes. Those countries whose population displayed extraversion also saw tipping size increased with national extraversion. Conversely, tipping size decreased with increased levels of psychoticism. It is important to note that this study used secondary national data about personality traits and tipping norms to draw its conclusions.

\subsection{Meal Duration and the Dinning Process}

The restaurant dining experience can be defined as a six stage process that includes prearrival, postarrival, preprocess, in-process, postprocess, and table turnover (Kimes, 2008). Meal duration begins when 
the customer is first seated and ends once the customer pays the bill. Using Kimes' (2008) outline, meal duration is defined from preprocess to postprocess. While research is limited about meal duration's relationship with tipping, there is an abundance of researching concerning the importance of the dining process and its relationship to customer satisfaction, employee satisfaction, and restaurant financial performance (Kimes, 2008). In turn, the relationship of tipping and meal duration could prove to be robust.

\subsection{Other Variables}

There have also been recent studies that introduce new variables that correlate with tipping. Conlin at al. (2003) discusses a relationship between tipping and prosocial music lyrics. Their results showed that when restaurant patrons were exposed to music with prosocial lyrics there was a significant increase in their tipping behavior. Conlin at al. (2003) conducted a study on tipping and waitresses' facial cosmetics. This study showed that both men and women were more likely to tip a waitress who was using facial makeup compared to a waitress who was not wearing any facial makeup. Seiter (2007) showed that customers leave significantly larger tips when the server complimented their order choice compared to when the server did not. Kerr and Domazilcky (2009) found that elderly people tend to tip less. This relates to the elderly tipping almost six and a half percentage points less than that of their youngest customers. Lynn and Sturman (2010) showed that alcohol consumption of any kind had a positive coefficient relating to tipping percentage.

\section{Methodology}

\subsection{Data collection}

Business students at a university in a large southeastern city were asked to complete a tipping journal. In the journal, subjects were asked to record information about themselves and information about each time they ate at restaurant over a one-month period. Initially, a pilot test of the survey was conducted amongst a group of 25 college students and multiple research faculty to ensure the quality and clarity of the measurement items in the survey.

Students were also asked to attach receipts to their journal entries to ensure the accuracy of the information they provided. In order to isolate only the restaurant experiences with table service that are of interest to this study, dining experiences were only retained for analysis if they involved (a) eating in the restaurant, (b) waiter/waitress service, (c) non-zero bill contributions from the participant, and (d) meal duration was recorded and more than 25 minutes. The purified data set contained information about 248 dining occurrences experienced by 68 participants. The number of dining experiences from each participant ranged from one to six with a mean of about 3 .

\subsection{Questionnaire development}


First, students were asked to record personal information, including their past hospitality work experience, demographic information and take a short personality test. This included their gender, age in years, race identification, and a yes or no question indicating whether or not they had experience working in the restaurant or related industry. Then, students were asked to fill out a Ten-Item Personality Inventory (TIPI). This is a ten-question survey that is used by researchers as a quick and effective measure of the "Big Five" personality types (Gosling et al., 2003). The results of this brief test create an individual's ranking on the following Big Five factors: openness, conscientiousness, extroversion, agreeableness, and neuroticism [with a scale with $2=$ lowest score to $14=$ highest score].

For the remaining portion of the tipping journal, students were asked to record information about their experiences dining out at restaurants. Among the information recorded was the following: (1) date and time; (2) name of the establishment; (3) meal type (breakfast, lunch, dinner, just drinks); (4) total time spent at the establishment (recorded in minutes); (5) bill contribution (amount of the total bill, not including tip, that the participant was personally responsible for paying); (6) tip (dollars and cents amount that the participant left as a tip; this amount was divided by the bill contribution to obtain a measure of tip percentage); (7) dessert (whether or not the participant had a dessert); (8) alcohol (number of alcoholic drinks consumed while dining); (9) amount spent on beverage (portion of the participants contribution that was spent on any beverages); (10) server gender; (11) server race; (12) service quality and experience rating (a 13 question rating system of aspects of service on a 10 -point scale [with $1=$ poor and $10=$ excellent] including server presentation skills, server appearance, server friendliness, server attentiveness, server promptness, food appearance, food taste, food portion size, food value for the money, dining room lighting, dining room temperature, dining room noise level, dining room crowd level).

\subsection{Data analysis}

The data were analyzed with the SPSS version 19. Descriptive statistics were used to describe the respondents' socio-demographic profiles, and linear regression analysis and hierarchical linear modeling were used to test the relationship between tipping amount and its predictors.

\section{Results}

\subsection{The profile of respondents}

Table 1 shows the socio-demographic characteristics of the respondents. Of the 68 participants 47 were females. The respondent's ages ranged from 18 to 46 with an average age at about 21. Further analysis indicated that 55 of those surveyed were White. Furthermore, $76 \%$ of those surveyed indicated that they had experience working in the hospitality or related field. Dining experience level variables were also analyzed. There were a total of 248 dining experiences included. Bill size ranged from 1.75 dollars to 
107.53 dollars while tips on those bills ranged from .50 to 20.00 dollars. Further analysis revealed that the average meal duration was about 1 hour and 16 minutes with half of all the dining experiences taking place on the weekend. During the meal, 23\% of respondents consumed at least one alcoholic beverage and only $6 \%$ of respondents chose to have dessert. Furthermore, analysis of server demographics indicated that $78 \%$ of servers were White and $70 \%$ of servers were females. Service quality, atmosphere and food quality variables were also analyzed for frequency. To create the service index, atmosphere index and food quality index, all the individual ratings were averaged together for each category. The ranges of service rating were from 1.60 to 10.00 with a mean rating of 7.07. The minimum value of atmosphere was 2.00 and maximum was 10.00 with a mean rating of 7.49 . The minimum and maximum for food rating was 2.25 and 10.00 , respectively with a mean rating of 8.12 .

Table 1. Descriptive statistics of variables used

\begin{tabular}{|c|c|c|c|c|c|}
\hline Item & $\mathrm{N}$ & Min. & Max. & Mean & Std. Dvt. \\
\hline \multicolumn{6}{|l|}{ Customer Level Variables } \\
\hline $\operatorname{Sex}^{\mathrm{a}}$ & 68 & .00 & 1.00 & .69 & .46 \\
\hline Age & 68 & 18.00 & 46.00 & 21.32 & 3.16 \\
\hline Race $^{\mathrm{b}}$ & 68 & .00 & 1.00 & .80 & .39 \\
\hline Hospitality work experience ${ }^{c}$ & 68 & .00 & 1.00 & .76 & .42 \\
\hline Name of dining experience & 68 & 1.00 & 6.00 & 2.85 & 1.49 \\
\hline \multicolumn{6}{|c|}{ Dining Experience Level Variables } \\
\hline Tip & 248 & .89 & 20.00 & 3.73 & 2.74 \\
\hline Bill & 248 & 1.75 & 107.53 & 17.75 & 14.89 \\
\hline Food portion of bill & 247 & .00 & 107.53 & 15.39 & 13.52 \\
\hline Beverage portion of bill & 247 & .00 & 47.41 & 2.39 & 4.58 \\
\hline Table-time & 242 & 20.00 & 190.00 & 75.94 & 32.45 \\
\hline Number of alcoholic beverage & 248 & .00 & 6.00 & .50 & 1.08 \\
\hline Dinner $^{d}$ & 248 & .00 & 1.00 & .60 & .49 \\
\hline Alcohol ${ }^{\mathrm{e}}$ & 248 & .00 & 1.00 & .23 & .42 \\
\hline Dessert ${ }^{\mathrm{f}}$ & 245 & .00 & 1.00 & .06 & .23 \\
\hline Weekend ${ }^{g}$ & 248 & .00 & 1.00 & .50 & .50 \\
\hline Server sex ${ }^{h}$ & 247 & .00 & 1.00 & .70 & .45 \\
\hline Server race ${ }^{\mathrm{i}}$ & 248 & .00 & 1.00 & .78 & .41 \\
\hline Food index & 248 & 10.00 & 10.00 & 8.11 & 1.36 \\
\hline Atmosphere index & 248 & 10.00 & 10.00 & 7.48 & 1.75 \\
\hline Service index & 248 & 10.00 & 10.00 & 7.07 & 1.77 \\
\hline
\end{tabular}

${ }^{a}$ Sex: $1=$ female, $0=$ male; ${ }^{\mathrm{b}}$ Race: $1=$ white, $0=$ other; ${ }^{\mathrm{c}}$ Hospitality work experience: $1=y e s, 0=$ no;

d Dinner: 1=dinner, 0=breakfast or lunch;

e Alcohol: 1=consumed at least one alcoholic drink, $0=$ zero alcoholic drinks consumed;

${ }^{\mathrm{f}}$ Dessert: $1=$ yes, $0=$ no; ${ }^{\mathrm{g}}$ Weekend: $1=\mathrm{F}$, Sa, or Su, $0=$ other;

${ }^{\mathrm{h}}$ Server sex: $1=$ female, $0=$ male; ${ }^{i}$ Server race: $1=$ white, $0=$ other.

\subsection{Linear regression analysis}


A linear regression analysis was performed to determine the coefficients of variables believed to impact tipping amount in dollars. The data were analyzed using a multiple regression analysis method. This regression used a within-subject data and estimated the regression coefficients. The first model predicted tip amount (in dollars and cents) using food portion bill, beverage portion of the bill, the 5 Big Ten personality types, time (in minutes), the four individual ratings of the food, the four individual ratings of the atmosphere, the five individual ratings of service, consumer gender, server gender, whether or not the participant had hospitality experience, whether or not the server was White, whether or not the dining experience occurred on a weekend (Friday, Saturday, Sunday), and whether or not the dining experience involved consumption of alcohol as main predictors. The coefficient of the determination (R2)was found to be.812. The adjusted R2was.779. The F-ratio value was 25.274 with a $\mathrm{p}$-value of less than .01. This low $\mathrm{p}$-value indicates that it is very unlikely that the results of this regression model occurred by chance.

The results of this analysis indicated that tip amounts significantly increased with food portion of the bill, beverage portion of the bill, if the meal period was dinner, if the consumer was female, if the server was male, if the meal involved alcohol consumption, and the customer's friendliness rating of the server. Tip amounts increasing with food portion of the bill and beverage portion of the bill is consistent with the 15 to 20 percent tipping norm. Furthermore, the higher regression coefficient (beta $=.152$ ) associated with tipping toward food portion of the bill, compared to the lower coefficient (beta $=.116$ ) associated with beverage portion of the bill, is consistent with compensating the server for the extra time and effort it takes to serve food.

The positive effect of server friendliness makes sense because server friendliness is directly related to service quality. Server friendliness has been shown to be a direct predictor of tipping (Bodvarsson et al., 2003; Brewster, 2012a). This indicates that higher levels of service compensate the server for doing a good job. In this case, friendliness was found to be the main component of the service index that significantly impacted tip amount.

The positive beta of .952 associated with ordering an alcoholic beverage is consistent with other findings (Conlin et al, 2003). This could be due to both psychological factors and service related factors. The alcohol's ability to reduce people's cognitive abilities could account for an increase in tip amount. Consumers could become more sensitive to a positive experience (Steele and Josephs, 1990) and in turn be more willing to tip. Also, the positive beta associated with ordering an alcoholic beverage could reflect a reward for the server's extra effort (i.e. in the case involving the presentation of a bottle of wine). Under the same logic, the positive coefficient (beta $=.417$ ) associated with tipping more during dinner makes sense, as it takes the server more effort to serve during dinner because dinner often involves multiple courses.

The positive coefficient (beta $=.556$ ) indicates that female customers tend to tip more on average in terms of their gender. Alternatively, the negative coefficient - .369 indicates that male servers tend to receive higher tips in terms of their gender. It is significant that females tip more than males on average and that male servers receive higher tips. However, it has been shown that gender effects on tipping depend on the server/customer gender relationship (Conlin et al, 2003). This indicates that there could be more to the tipping-gender relationship than a one-dimensional linear relationship. 
Table 2. Linear regression analysis: predictors of customer tip amount

\begin{tabular}{|c|c|c|c|c|c|}
\hline Variables & B & SE B & $\beta$ & $\mathrm{t}$ & Sig. \\
\hline Extroversion & .043 & .095 & .018 & .453 & .651 \\
\hline Agreeableness & -.089 & .113 & -.031 & -.789 & .431 \\
\hline Conscientiousness $* * * *$ & -.452 & .125 & -.132 & -3.616 & .000 \\
\hline Emotional Stability**** & .485 & .111 & .177 & 4.370 & .000 \\
\hline Openness & .217 & .138 & .068 & 1.574 & .117 \\
\hline Time & -.005 & .003 & -.054 & -1.384 & .168 \\
\hline Dessert $(\mathrm{Y} / \mathrm{N})$ & .334 & .523 & .024 & .637 & .525 \\
\hline Beverage Portion of Bill*** & .116 & .044 & .150 & 2.665 & .008 \\
\hline Server Appearance & -.003 & .093 & -.002 & -.027 & .978 \\
\hline Server Friendliness*** & .268 & .090 & .176 & 2.963 & .003 \\
\hline Server Attentiveness & -.080 & .103 & -.060 & -.777 & .438 \\
\hline Server Promptness & .096 & .094 & .075 & 1.022 & .308 \\
\hline Food Appearance & -.056 & .103 & -.034 & -.546 & .586 \\
\hline Food Taste & .014 & .111 & .008 & .128 & .899 \\
\hline Portion Size & -.025 & .099 & -.014 & -.248 & .804 \\
\hline Food Value for Money & .125 & .092 & .069 & 1.352 & .178 \\
\hline Room Lighting & -.002 & .082 & -.001 & -.020 & .984 \\
\hline Room Temperature & -.003 & .073 & -.002 & -.046 & .963 \\
\hline Room Noise Level & -.088 & .069 & -.089 & -1.275 & .204 \\
\hline Room Crowd Level & .084 & .067 & .090 & 1.253 & .212 \\
\hline Server Presentation Skill & .000 & .094 & .000 & -.003 & .997 \\
\hline Dinner $(\mathrm{Y} / \mathrm{N}) * *$ & .447 & .222 & .078 & 2.012 & .046 \\
\hline Consumer Hospitality Experience & .312 & .270 & .044 & 1.159 & .248 \\
\hline Server White & .267 & .248 & .038 & 1.073 & .285 \\
\hline Weekend & .181 & .212 & .032 & .852 & .395 \\
\hline Consumer White & -.313 & .297 & -.044 & -1.053 & .294 \\
\hline Alcohol Consumed $* *$ & .952 & .395 & .140 & 2.408 & .017 \\
\hline Food Portion of Bill $* * * *$ & .152 & .008 & .734 & 18.436 & .000 \\
\hline Consumer Sex** & .556 & .264 & .085 & 2.106 & .037 \\
\hline Server Sex* & -.369 & .213 & -.060 & -1.736 & .084 \\
\hline
\end{tabular}

$\mathrm{R}=.901, \mathrm{R}^{2}=.812$, adjusted $\mathrm{R}^{2}=.779, \mathrm{~F}=25.274, \mathrm{p}<.001 ; \mathrm{p}<.10, * * \mathrm{p}<.05, * * * \mathrm{p}<.01, * * * * \mathrm{p}<.001$

Finally, two of the Big Five personality types were found to be significant in predicting tip amount. The items from Gosling, Rentfrow and Swann's (2003) ten item measure of the Big Five personality traits did load on the five expected factors. Cronbach's sub scale reliabilities were acceptable levels for exploratory research (Gall, Gall and Borg, 1999) and ranged from .605 to .743 (see Table 3). 
Table 3. Reliability test: big five personality trait scale

\begin{tabular}{|c|c|}
\hline Big Ten Item (Sub Level Questions indicating I see myself as $\cdots$ ) & Cronbach's Alpha \\
\hline Extroversion(Extraverted/Enthusiastic vs. Reserved/Quiet) & .743 \\
\hline Agreeableness (Sympathetic/Warm vs. Critical/Quarrelsome) & .605 \\
\hline Conscientiousness (Dependable/Self-Disciplined vs. Disorganized/Careless) & 654 \\
\hline Emotional Stability(Calm/Emotionally Stable vs. Anxious/Easily Upset) & .611 \\
\hline Openness (Open to New Experiences/Complex vs. Conventional/Uncreative) & .618 \\
\hline
\end{tabular}

Note: Gosling, Rentfrow and Swann's (2003) ten item measure of the Big Five personality trait scale

Tip amounts increased with higher levels of emotional stability with a beta of .485. Tip amounts also decreased with higher levels of conscientiousness with a beta of -.452 . There is very little previous data concerning the Big Five personality traits and their relationship to tipping. However, the Big Five personality trait of conscientiousness reflects a tendency to be hardworking, responsible, and self-disciplined (Shafer, 1999). People with high levels of conscientiousness may be more reluctant to tip or may be more reluctant to tip additional amounts that deviate from their personal tipping standard. The Big Five personality trait of emotional stability reflects a tendency to be clam, relaxed, happy and not irritated easily (Shafer, 1999). While the intuition for the positive coefficient related to tipping amount and emotional stability is unclear, it could be related to an overall lack of unstable emotional reaction. The conclusion that can be drawn here is that personality types could have an effect on tipping and, therefore, more research should be done to conclude personality's true impact on tipping.

Overall, the linear regression model produced many findings that reciprocate past results, as well as, findings that should inspire further studies. However, some variables found to be significant in linear regression model created a need for further analysis. The variables of particular interest were bill size, food quality index, atmosphere quality index, service quality index, whether the dining experience involved alcohol consumption, and the customer/server gender dynamics. The next section will incorporate some of the main influencers of tipping from the linear regression plus the interactions amongst those main factors using hierarchical linear modeling.

\subsection{Hierarchical linear modeling Bill, dining experience indices, and alcohol}

The first set of models show bill amount, the cumulative rating for food, the cumulative rating of service, cumulative rating of atmosphere, whether or not the visit involved alcohol consumption and interactions amongst those variables (Table 4). Model 1 begins with the variables of bill, food index, atmosphere index, and service index. This model shows that both bill and service index have significantly positive relationship with tipping amount with betas of .15 ( $\mathrm{p}<.001)$ and .26 ( $\mathrm{p}<.001)$, respectively. By adding in the dummy variable representing alcohol consumption, the explanation power (R-Square) increases from .730 to .738. Model 2 in Table 4, the service index as, well as the bill size positively influence tip amount with a beta of .25 ( $\mathrm{p}<.001)$ and .15 ( $\mathrm{p}<.001)$, respectively. Alcohol consumption also positively influences tip amount 
$(b=.63, p<.01)$.

When looking at the interactions amongst alcohol consumption with bill size, service index, food index and atmosphere index, R-Square increases to .749. The only variable that significantly moderates the effects of alcohol consumption was the consumer's cumulative food rating (see Table 4, Model 3). Surprisingly, those customers who consumed alcohol took into the effect of the food rating when considering tipping amount. This makes sense because it accounts for very low food ratings having a negative impact on tipping. In other words, under the condition that alcohol is consumed, when food quality rises consumers pay higher tips. Conversely, under the condition that alcohol is consumed, when food quality falls, consumers pay lower tips. The remaining three variables do not interact with alcohol consumption.

Table 4. Hierarchical regression analysis: predictors of customer tip amount $(N=248)$

\begin{tabular}{|c|c|c|c|c|c|c|c|c|c|}
\hline & \multicolumn{3}{|c|}{ Model 1} & \multicolumn{3}{|c|}{ Model 2} & \multicolumn{3}{|c|}{ Model 3} \\
\hline Variable & B & SE B & $\beta$ & B & SE B & $\beta$ & B & SE B & $\beta$ \\
\hline Bill & 0.15 & 0.01 & $.82 * * * *$ & 0.15 & .01 & $.79 * * * *$ & 0.15 & 0.01 & $.80 * * * *$ \\
\hline Food & 0.03 & 0.08 & .02 & 0.04 & .08 & .02 & -0.03 & 0.09 & -.02 \\
\hline Atmosphere & -0.04 & 0.06 & -.03 & -0.04 & .06 & -.02 & -0.02 & 0.06 & -.01 \\
\hline Service & 0.26 & 0.06 & $.17 * * * *$ & 0.25 & .06 & $.16 * * * *$ & 0.23 & 0.07 & $.15 * * *$ \\
\hline Alcohol Consumption & & & & 0.63 & .23 & $.10 * * *$ & -2.93 & 1.51 & $-.46 *$ \\
\hline Alch. C. x Bill & & & & & & & 0.00 & 0.01 & -.01 \\
\hline Alch. C. x Food & & & & & & & 0.46 & 0.20 & $.52 * * *$ \\
\hline Alch. C. x Atmosphere & & & & & & & -0.20 & 0.18 & -.23 \\
\hline Alch. C. x Service & & & & & & & 0.18 & 0.15 & .21 \\
\hline$\Delta R^{2}$ & \multicolumn{3}{|c|}{0.730} & \multicolumn{3}{|c|}{0.008} & \multicolumn{3}{|c|}{0.011} \\
\hline$F-$ stat & \multicolumn{3}{|c|}{$164.167 * * * *$} & \multicolumn{3}{|c|}{$136.475 * * * *$} & \multicolumn{3}{|c|}{$79.59 * * * *$} \\
\hline
\end{tabular}

\subsection{Bill, dining experience indices, and customer/server gender dynamics}

Table 5 shows bill amount, the cumulative rating for food, the cumulative rating of service, cumulative rating of atmosphere, and all the possible gender dynamics (using the female customer to female server relationship as the base group), and their interactions. Model 2 begins with the variables of bill, food index, atmosphere index, service index and the addition of three gender dynamic variables, female customer with a male server, male customer with a male server, and male customer with a female server. The variable for female customer with a female server is used as the base group. When adding in the three gender-dynamic variables in the model that includes bill and dining indices, explanation power increases up to .739. The model shows that female customers have a tendency to tip male servers higher than they do female servers with a positive beta of .63. This would make sense as it replicates the findings of Conlin et al. (2003). In Table 4-Model 1 also shows that bill and service index are still significant influencers of tipping amounts with betas of $.15(\mathrm{p}<.001)$ and $.27(\mathrm{p}<.001)$, respectively. Model 2 shows the addition of the interactions amongst the gender dynamics with bill and the dining experience indices. The model increases the $\mathrm{R}$-Squared to .768. The only variable that significantly moderates the effects of gender dynamics is the in- 
teraction of bill size with a female customer and a male server with a beta of .06 ( $\mathrm{p}<.001$ ) (see Table 5, Model 2). This interaction indicates that when there is a female customer with a male server, as the bill gets higher the female customer pays higher tips. No other gender-dynamic interactions modify tipping amount.

Table 5. Hierarchical regression analysis with interaction terms $(\mathrm{N}=248)$

\begin{tabular}{|c|c|c|c|c|c|c|}
\hline \multirow{2}{*}{ Variable } & \multicolumn{3}{|c|}{ Model 1} & \multicolumn{3}{|c|}{ Model 2} \\
\hline & B & SE B & $\beta$ & B & SE B & $\beta$ \\
\hline Bill & 0.15 & 0.01 & $.83 * * * *$ & 0.14 & 0.01 & $.78 * * * *$ \\
\hline Food & 0.03 & 0.08 & .01 & -0.08 & 0.11 & -0.04 \\
\hline Atmosphere & -0.04 & 0.06 & -.03 & -0.01 & 0.07 & -0.01 \\
\hline Service & 0.27 & 0.06 & $.18 * * * *$ & 0.29 & 0.09 & $.19 * * * *$ \\
\hline $\mathrm{FM}^{\mathrm{a}}$ & 0.63 & 0.23 & $.09 * * *$ & -0.74 & 1.52 & -0.11 \\
\hline $\mathrm{MF}^{\mathrm{b}}$ & 0.03 & 0.25 & .00 & 0.29 & 2.01 & 0.04 \\
\hline $\mathrm{MM}^{\mathrm{c}}$ & -0.06 & 0.32 & -.01 & -1.65 & 2.42 & -0.17 \\
\hline Bill x FM & & & & 0.06 & 0.02 & $.21 * * * *$ \\
\hline Bill x MF & & & & -0.02 & 0.02 & -0.06 \\
\hline Bill x MM & & & & -0.01 & 0.02 & -0.03 \\
\hline Atmosphere x FM & & & & -0.23 & 0.19 & -0.26 \\
\hline Atmosphere $\mathrm{x}$ MF & & & & -0.04 & 0.22 & -0.04 \\
\hline Atmosphere x MM & & & & 0.12 & 0.20 & 0.09 \\
\hline Food x FM & & & & 0.21 & 0.21 & 0.26 \\
\hline Food $\times$ MF & & & & 0.19 & 0.22 & 0.20 \\
\hline Food x MM & & & & 0.23 & 0.33 & .20 \\
\hline Service x FM & & & & 0.53 & 0.16 & .06 \\
\hline Service x MF & & & & -0.17 & 0.15 & -.16 \\
\hline Service x MM & & & & -0.14 & 0.29 & -.10 \\
\hline$\Delta R^{2}$ & & & 0.739 & & & 0.029 \\
\hline$F-$ stat & & & $96.912 * * * *$ & & & $39.589 * * * *$ \\
\hline \multicolumn{7}{|c|}{$* \mathrm{p}<.10, * * \mathrm{p}<.05, * * * \mathrm{p}<.01, * * * * \mathrm{p}<.001$} \\
\hline \multicolumn{7}{|c|}{ FM- Female Customer with Male Server $=1$, otherwise $=0$} \\
\hline \multicolumn{7}{|c|}{ b $\mathrm{MF}$ - Male Customer with Female Server $=1$, otherwise $=0$} \\
\hline \multicolumn{7}{|c|}{${ }^{\mathrm{c}}$ MM - Male Customer with Male Server $=1$, otherwise $=0$} \\
\hline
\end{tabular}

\section{Conclusions and discussion}

Tipping is intended to be a reward for quality service. That is to say, that better service should increase tip amounts. Past studies have shown that it does (Azar, 2009). Our study was able to replicate the service-tipping relationship. Moreover, this study reiterated that server friendliness is a very powerful tool to increasing tips. While this study was able to produce results that strongly indicate that service has a positive relationship with tip amount, it failed to show that service interacts with other variables to affect tip amounts. Nevertheless, the main take-away from this study regarding service is that the service-tipping relationship is strong and does not vary in strength as much as the previous literature suggests. 
In addition, the personality and tipping relationship was tested here using the Big Five. While this analysis did produce a positive relationship with emotional stability and a negative relationship to conscientiousness, the results need further validation. What can be said is that this study shows an empirical support of a significant relationship between personality types and tipping. There is no doubt that this relationship deserves further study.

Furthermore, this study was able to show that other variables, as well as, some of their interactions have a strong effect on tipping amount. Some variables that influence the customer's tip amount are customer food portion of the bill, beverage portion of the bill, whether or not the dining experience took place during dinner, whether or not alcohol was consumed, and consumer sex (more specially the female customer/male server gender dynamic). Each is discussed in detail below.

Bill size has been shown to have a very strong relationship to tip size (Lynn, 1988). This relationship makes sense because of the 15 to 20 percent social norm. This study was able to replicate that finding. However, this study divided bill into the two categories of the beverage portion of bill and the food portion of bill. While both have a strong positive relationship with tipping amount, we found that food portion of the bill increases tipping amount at a faster rate. In other words, customers tip a higher percentage on food than they do on drinks. One reason could be the customer's reward to the server for the extra effort it takes to serve food. Under the same logic, tip amount seems to go up when the meal takes place during dinner time. Again, this effect could represent the customer compensating the server for the extra effort it takes to serve dinner.

Another factor influencing tipping amount was alcohol consumption. The positive effect alcohol has on tipping amount is consistent with previous research (Sanchez, 2002). There could be many reasons for this positive effect. The positive effect could be a customer's reward for the extra effort it takes the server to serve alcohol. Alcohol limits a person's ability to respond to cues that could limit this increased tipping behavior. This study also found that alcohol consumption interaction with food service rating index is statistically significant. In other words, under the condition that alcohol is consumed, the higher the food service rating the higher the tip amount. Conversely, under the condition that alcohol is consumed, the lower the food service rating the lower the tip amount. This studied showed that "prosocial" hypothesis can work to lower tipping amount in the case of a negative experience, especially low quality food.

Gender was also found to have a strong relationship on tipping. While some studies have found that males tip more than females (e.g., Crusco and Wetzel, 1984), this was not the case in this study. This study found that females tip higher amounts on average than males. What is believed to be most important when regarding gender and tipping, is not just the consumer gender or just the server gender, but the gender dynamic. When taking into account for the customer/server gender dynamic, this study found that females tend to tip male servers higher than they do female servers. Consistent with previous findings (Conlin et al, 2003), this effect is believed to be because of the dynamics of sexual attractiveness. This study also found that the female customer/male server relationship interacts with bill size. In other words, females tip male servers a higher amount as the bill gets higher, compared to a female server. This is an interesting finding because it negates the case of "the magnitude effect" (Green et al, 2003), under the condition of 
a female customer and a male server.

\subsection{Managerial implications}

In addition to the empirical findings, this study presents many incentives that can be used to benefit customers, servers and managers alike. Under the context of this study, the servers who would receive the highest tips are those who are the most affable, increase their average check, serve alcohol, work during dinner, and exploit gender dynamics. To help incentivize server to perform, managers should take actions that can potentially increase server tips. In turn, these actions should increase customer satisfaction and customer dining frequency.

Service quality, specifically server friendless, has been shown to increase tip amounts. Managers should encourage courtesy and a positive demeanor as a key component of service excellence. Other research has suggested many ways to display friendliness like, writing "Thank You" on the bill, kneeling down next to the table, smiling, introducing themselves by name, and calling customers by name (Lynn, 2005). Managers should stress the relationship of these techniques to the tips servers receive because these techniques have been shown to increase tips 20 percent on average (Lynn, 2005).

Managers should also encourage the up selling of food and alcohol. By serving more food and alcohol, servers can increase their average check. Because many people choose to tip using a percentage of their bill, up selling should increase servers' tips. Knowing this, managers should train employees in the effective and proper techniques of up selling. Moreover, this study shows that consumption of at least one alcoholic beverage has the ability to increase tips. Managers should encourage customers to order drinks, for example, by offering drink specials. These drink specials will simultaneously increase alcohol consumption, average check and tip amount.

Managers should also begin to understand the power of gender dynamics. This study shows that females tip male servers higher on average. Managers should be able to use this information to the servers' advantage. For example, managers should assign male servers to tables that are composed of a large group of females. In turn, this should increase the tip amount left by that table.

It is also important realize that implementing these techniques benefits managers. By using a combination of these techniques, mangers should see an increase in customer satisfaction, an increase in revenues and decrease in server turnover.

\subsection{Limitations and suggestions for future research}

This study is not free from limitations. One concern about the methodology of this study is that the tip amount was self-reported. Tip amounts could have been altered to make the customer seem generous or to tie the tip amounts more consistently with service ratings. To help mitigate some of this bias, a copy of the receipt was requested with every journal entry. Additionally, a researcher could directly monitor tip amounts from the server's perspective as a means to completely eliminate any self reported bias. 
Another limitation of this study is that tipping was examined using student sample, which hinders the generalizability of the findings. Nevertheless, it is believed that this study is relevant because the survey data is used primarily to test the causal relationship between predictors and tipping amount. Furthermore, the findings make a contribution to the knowledge base of restaurant tipping. Another limitation arises from its analysis. Since random-effects based hierarchical analysis may capture all the unobserved heterogeneities among consumers, future researchers need to employ fixed-effects analysis. In addition, future researchers need to include pother influential factors such as a customer's social norm and social influence of companion's tipping behavior to enhance the explanatory power of the regression model.

The culmination of this research and the recognition of its limitations have presented many opportunities for future studies involving the predictors of consumer tipping amounts. While this study was able to quantify the impact of consumer personality traits on tipping, the results need further validation across a broad sample. Future studies could examine consumer personality types using scales other than the Big Five. Furthermore, future studies could seek to understand the logical relationship between personality types and tipping.

Next, future research should seek information related to tipping across different sectors of full service restaurants (i.e. luxury versus casual). Furthermore, studies seek to replicate our findings, as well as, identify more predictors of tipping amount. Some examples of these additional predictors are the six components of the dinning process (Kimes, 2008), customer comfort level, restaurant cleanliness, advanced service techniques (i.e. replacing the phrase "no problem" with "my pleasure"), the occurrence of service failure/recovery.

It is also recommended that future studies seek to use a random sample, as opposed to any homogeneous sample. In conjunction, future studies should use a larger sample size than that of this study to warrant the validity of the survey results.

Finally, future studies should try to understand tipping as it implies to other hospitality sectors. These other settings include, but are not limited to, valet parking, bell service, fine dining, buffet dining, airport luggage service, large party banquets, bars, night clubs, tour service, and spas.

\section{REFERENCES}

Ashton, M. C. 1998. "Personality and job performance: the importance of narrow traits." Journal of Organizational Behavior 19:289-303.

Azar, 0. H. 2003. "The implications of tipping for economics and management" International Journal of Social Economics 30:1084-1094.

Azar, 0. H. 2004. "What sustains social norms and how they evolve? The case of tipping." Journal of Economic Behavior and Organization 54:49-64.

Azar, 0. H. 2007. "The social norm of tipping: a review." Journal of Applied Social Psychology 37(2):380-402.

Azar, 0. H. 2009. "Incentives and service quality in the restaurant indutry: the tipping-service puzzle." Applied Economics 41(15):1917-1927. 
Bodvarsson, 0. B., and Gibson, W. A. 1994. "Gratuities and customer appraisal of service: evidence from minnesota restaurants." Journal of Socio-Economics 23:287-302.

Bodvarsson, 0. B., Luksetich, W. A., and McDermott, S. 2003. "Why do diners tip: rule-of-thumb or valuation of service?.” Applied Economics 35:1659-1665.

Brewster, Z. W. 2012. "Racialized customer service in restaurants: a quantitative assessment of the statistical discrimination explanatory framework." Sociological Inquiry 82(1):3-28.

Brewster, Z. W. 2012. "The effects of restaurant servers' perceptions of customers' tipping behaviors on service discrimination." International Journal of Hospitality Management 32:228-236.

Brewster, Z. W. 2012. "Racially discriminate service in full-service restaurants: the problem, cause, and potential solutions.” Cornell Hospitality Quarterly 53(4):274-285.

Brewster, Z. W., and Rusche, S. N. 2012. "Quantitative evidence of the continuing significance of race: tableside racism in full-service restaurants." Journal of Black Studies 43(4):359-384.

Conl in, M., Lynn, M., and 0' Donoghue, T. 2003. "The social norm of restaurant tipping." Journal of Economic Behavior and Organization 52:297-321.

Crusco, A. H., and Wetzel, C. G. 1984. "The Midas Touch: The Effects of Interpersonal Touch on Restaurant Tipping.” Personality and Social Psychology Bullet in 10:512-517.

Freeman, S., M. R. Walker, R. Borden., and Latane, B. 1975. "Diffusion of responsibility and restaurant tipping: cheaper by the bunch." Personality and Social Psychology Bulletin 1:584-587.

Gall, J. P., Gall, M. D., and Borg, W. R. 1999. Applying educational research, 4th ed. MA: Longman.

Gosling, S. D., Rentfrow, P. J., and Swann, W. B. 2003. "A very brief measure of the big five personality domains." Journal of Research in Personality 37:504-528.

Green, L., Myerson, J., and Schneider, R. 2003. "Is there a magnitude effect in tipping?." Psychonomic Bullet in and Review 10(2):381-386.

Judge, T., Higgins, C., Thoresen, C., and Barrick, M. 1999. "The big five personality traits, general mental ability, and career success across the life span.” Personnel Psychology 52:621-652.

Kerr, P. M., and Domazlicky, B. R. 2009. "Tipping and service quality: results from a large database." Applied Economics Letters 16:1505-1510.

Kimes, S. E. 2008. "The role of technology in restaurant revenue management." Cornell Hospitality Quarterly 49(3):297-309.

Lynn, M. 1988. "The effects of alcohol consumption on restaurant tipping." Personality and Social Psychology Bullet in 14:87-91.

Lynn, M. 2005. "Increasing servers' tips: what managers can do and why they should do it." Journal of Foodservice Business Research 8:89-98.

Lynn, M. 2006. "Tipping in restaurants and around the globe: An interdisciplinary review." Handbook of Contemporary Behavioral Economics: Foundations and Developments 31:626-643.

Lynn, M. 2009. "Determinants and consequences of female attractiveness and sexiness: Realistic tests with restaurant waitresses." Archives of Sexual Behavior 38:737-745.

Lynn, M. 2011. "Race differences in tipping: testing the role of norm familiarity." Cornell Hospitality Quarterly 52:73-80.

Lynn, M., and Bond, C. F. 1992. "Conceptual meaning and spuriousness in ratio correlations: The case of restaurant tipping." Journal of Applied Social Psychology 22:327-341.

Lynn, M., and Grassman, A. 1990. "Restaurant tipping: an examination of three rational explanations." Journal of Economics Psychology 11:169-181.

Lynn, M. . and Graves. J. 1996. "Tipping: an incentive/reward for service?." Hospitality Research Journal 20:1-14.

Lynn, M., and Latane, B. 1984. "The psychology of restaurant tipping." Journal of Applied Social Psychology 14:551-563. 
Lynn, M., and McCall, M. 2000. "Gratitude and gratuity: A meta-analysis of research on the service-tipping relationship." Journal of Socio-Economics 29:203-214.

Lynn, M., and Sturman, M. 2003. "It' s simpler than it seems: An alternative explanation for the magnitude effect in tipping." International Journal of Hospitality Management 22:103-110.

Lynn, M., and Sturman, M. 2010. "Tipping and service quality: a within-subjects analysis." Journal of Hospitality and Tourism Research 34:269-265.

May, J. M. 1980. "Looking for tips: an empirical perspective on restaurant tipping." Cornell Hospitality Quarterly 20:6-13.

Naragon-Gainey, K., and Watson, D. 2012. Personality, Structure. Encyclopedia of Human Behavior, 2nd Ed.

Sánchez, A. 2002. "The Effect of Alcohol Consumption and Patronage Frequency on Restaurant Tipping." Journal of Foodservice Business Research 5:19-36.

Schwartz, Z. 1997. "The economics of tipping: tips, profits and the market's demand-supply equilibrium." Tourism Economics 3(3):478-488.

Seiter, J. S. 2007. "Ingratiation and gratuity: the effect of complimenting customers on tipping behavior in restaurants.” Journal of Applied Social Psychology 37:478-485.

Shafer, A. B. 1999. "Brief bipolar markers for the five factor model of personality." Psychological Reports 84:1173-1179.

Shamir, B. 1983. "A note on tipping and employee perceptions and attitudes." Journal of Occupational Psychology 56(3):255-259.

Steele, C. M., and Josephs, R. A. 1990. "Alcohol myopia: it' s prized and dangerous effects." American Psychologist 45:921-933.

Wessels, W. J. 1997. "Minimum Wages and Tpped Servers." Economic Inquiry 35:334-349. 